\title{
ANALISA KOMPOSISI MINYAK ATSIRI KULIT JERUK MANIS HASIL EKSTRAKSI METODE MICROWAVE HYDRODIFFUSION AND GRAVITY DENGAN GC-MS
}

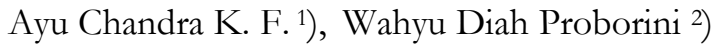 \\ 1,2) PS Teknik Kimia, Fakultas Teknik, Universitas Tribhuwana Tunggadewi Malang \\ email : ayu.chandra@unitri.ac.id
}

\begin{abstract}
This study aims to determine percent yield and chemical composition of volatile oil from citrus peel that extracted by using Microwave Hydrodiffusion and Gravity method. Chemical composition was analyzed using GasChromatography method. Based on gas chromatography analysis (GC) obtained 9 peaks with different retention time according to the type of compound that was analyzed. The highest peak comes with retention time of 8.440 with wide area $22623980(97,78 \%)$ and height 7241224 (96,70\%). Height is the distance from the base line to the maximum peak usually in mm, while the area is the area under the peak, and indicates the abundance of a component. Retention time is the time interval required by the solute (component) to get out of the column and reach the detector.
\end{abstract}

Keywords: citrus peel oil, Microwave Hydrodiffusion and Gravity (MHG), GC-MS

\section{PENDAHULUAN}

Meningkatnya jumlah sampah yang ada di masyarakat telah menjadi permasalahan yang cukup rumit untuk dipecahkan. Hal ini mendorong banyak orang untuk mengolah sampah tersebut menjadi produk atau barang yang lebih bernilai. Salah satunya adalah pemanfaatan limbah kulit buah menjadi sesuatu yang bernilai yaitu dengan ektraksi minyak atsiri kulit buah (Astarini, et al., 2010 dan Fong, 2012). Salah satu kulit buah yang dapat diekstrak adalah kulit jeruk manis (Citrus Sinensis), karena kulit jeruk manis dapat menghasilkan minyak atsiri yang dapat dimanfaatkan sebagai flavor, kosmetik/ parfum, dan industri sabun (Guenther, 1990).

Minyak atsiri merupakan hasil metabolisme sekunder yang dihasilkan oleh tanaman, bersifat volatil pada suhu kamar, dan berbau wangi (Sudaryanti dan Sugiharti, 1990). Komponen minyak kulit jeruk sebagai berikut : limonene $94 \%$, mirsen $2 \%$, oktanal $0.5 \%$, linalol $0.5 \%$, dekanal $0.4 \%$, neral $0.1 \%$, sitronelal $0.1 \%$, geranial $0.1 \%$, valensen $0.05 \%$, $\beta$-sinensial $0.02 \%$, dan $\alpha$ sinensial $0.01 \%$ (Tarwiyah, 2001).

Senyawa Limonene yang terdapat di dalam kulit jeruk inilah yang membuat minyak atsiri kulit jeruk mahal karena beraroma khas dan dapat dipakai sebagai bahan obat pengusir nyamuk bila dibakar (Megawati dan Kurniawan, 2015).

Teknik yang biasa digunakan untuk memperoleh minyak atsiri adalah melalui proses pengepresan, ekstraksi pelarut, penyulingan, enfleurasi, dan maserasi (Guenther, 1987). Oleh karena itu, perlu digunakan suatu metode ekstraksi alternatif yang ramah lingkungan, cepat, aman, dan hemat energi.

Dari penelitian sebelumnya didapatkan bahwa ekstraksi menggunakan microwave jauh lebih efektif, karena diperoleh kemurnian produk yang tinggi dan rendemen yang banyak, waktu proses yang cepat dan sedikitnya pemakaian solvent (Ferhat, 2006). 
Selanjutnya dikembangkan juga metode Microwave Hydrodiffusion and Gravity (MHG) yang menggabungkan pemanasan microwave dengan pemanfaatan gravitasi bumi pada tekanan atmosferik, tanpa ditambah pelarut organik ataupun air. Sehingga cukup memanfaatkan fenomena fisik, hidrodiffusi tanpa destilasi dan evaporasi (Chemat, et al., 2008).

Uji GC-MS digunakan untuk mengetahui kandungan senyawa kimia minyak atsiri kulit jeruk (Megawati dan Kurniawan, 2015). Keunggulan metode GC-MS adalah waktu identifikasinya cepat, sensitifitas yang tinggi, pemisahan yang baik, dan alat dapat dipakai dalam waktu lama (Sastrohamidjojo \& Pranowo, 1985).

\section{METODE PENELITIAN}

Bahan yang digunakan yaitu kulit jeruk manis (Citrus Sinensis). Alat utama yang digunakan yaitu Microwave merk Panasonic model NN-ST651M (multi-mode), dengan frekuensi magnetron $2,45 \mathrm{GHz}$, daya maksimum 1000 Watt, kapasitas 32 liter, dan dimensi : $\mathrm{p}=36,5 \mathrm{~cm}, 1=35,5 \mathrm{~cm}, \mathrm{t}=$ $25 \mathrm{~cm}$. Dilengkapi dengan reaktor berbentuk labu alas bulat berkapasitas 2 liter terbuat dari kaca pyrex serta dilengkapi pengatur waktu dan daya, bak penampung air pendingin, kondensor, corong pemisah (Florentine flask). Analisa komponen minyak atsiri menggunakan GC-MS.

\section{Variabel Penelitian}

1) Variabel Tetap

- Tekanan Atmosferik $1 \mathrm{~atm}$

- Massa kulit jeruk 400 gram

- Bahan yang digunakan dalam penelitian ini adalah kulit jeruk segar dan sudah dirajang

- Daya yang digunakan dalam penelitian ini adalah 100 watt
2) Variabel berubah

- Waktu ekstraksi yang digunakan adalah 15, 30, dan 45, 60 (menit)

\section{Prosedur Penelitian}

Kulit jeruk segar dipotong dengan ukuran $1 \mathrm{~cm}$, kemudian ditimbang sebanyak 400 gram dan diekstraksi dengan microwave bydrodiffusion and gravity dengan daya $100 \mathrm{watt}$ dengan waktu ekstraksi selama 15, 30, 45 dan 60 menit. Minyak yang diperoleh dipisahkan dari air dengan menggunakan corong pemisah, kemudian minyak tersebut dimasukkan kedalam botol sampel dan disimpan di dalam freezer (suhu $4^{\circ} \mathrm{C}$ ) untuk memisahkan sisa air dalam minyak. Kemudian minyak dianalisa komposisinya dengan GC-MS.

\section{HASIL DAN PEMBAHASAN}

Dalam penelitian ini, metode
ekstraksi dilakukan menggunakan microwave karena pemanasannya bersifat volumetrik dimana pemanasan langsung ke seluruh volume kulit jeruk sehingga proses ektraksinya cepat (tidak membutuhkan waktu yang lama). Pada pemanasan menggunakan microwave, terjadi perpindahan massa dan panas yang bekerja dalam arah yang sama yaitu dari dalam bahan menuju ke luar permukaan bahan. Menurut Soesanto (2007), penggunaan energi gelombang mikro pada microwave termasuk mekanisme perpindahan panas secara radiasi. Radiasi merupakan perpindahan panas dari suatu benda ke benda lainnya, tanpa adanya kontak fisik, melalui gerakan gelombang.

Menurut Taylor (2005), prinsip dasar pemanasan microwave karena adanya agitasi ion-ion yang bergerak atau molekul-molekul polar yang disebabkan gerakan medan 
magnetik /elektrik. Pergerakan partikelpartikel tersebut dibatasi oleh gaya pembatas (ketahanan dielektrik dan interaksi partikel). Hal ini mengakibatkan gerakan partikel tertahan dan menimbulkan gerakan acak sehingga menghasilkan panas.

Kombinasi sinergis fenomena perpindahan ini mempercepat proses difusi minyak menuju permukaan bahan. Minyak dan air akan turun secara gravitasi melewati kondensor. Di dalam kondensor, uap minyak dan air akan dikondensasi menjadi cair. Proses ekstraksi dilakukan selama 60 menit. Pengukuran suhu destilat dilakukan tiap 15 menit setelah minyak mulai menetes. Pengukuran suhu dilakukan untuk mengetahui rate destilat yang diperoleh. Minyak mulai menetes pada menit ke 10. Ketika radiasi gelombang micro diserap oleh kulit jeruk maka dinding sel akan perlahan rusak dan minyak yang tekandung dalam kulit jeruk akan perlahan-lahan menetes keluar bersama air. Seiring dengan bertambahnya waktu ekstraksi, jumlah rendemen yang dihasilkan semakin meningkat hingga menit ke 60 seperti yang ditunjukan pada Tabel 1. Setelah menit ke 60, peningkatan jumlah rendemen yang dihasilkan kurang signifikan, karena kandungan minyak dalam bahan baku (kulit jeruk manis) telah berkurang. Hal ini sesuai literatur yang menyatakan bahwa proses ekstraksi minyak pada awal proses penyulingan berlangsung cepat (menghasilkan banyak rendemen), dan secara bertahap semakin berkurang hingga sekitar 2/3 minyak telah tersuling (Wildan Habibi et al, 2013). Minyak yang diperoleh dimasukkan ke dalam corong pemisah untuk memisahkan campuran minyak dengan air. Pada saat proses ekstraksi berlangsung, kandungan air dalam kulit jeruk akan menguap terlebih dahulu dan minyak ikut teruapkan bersama air, sehingga minyak yang dihasilkan akan bercampur dengan air.

Berikut Tabel 1 yang merupakan hasil pengukuran volume minyak pada proses ekstraksi menggunakan microwave bydrodiffusion and gravity (MHG)

Tabel 1. Data Pengamatan Hasil Ekstraksi Minyak Atsiri Kulit Jeruk

\begin{tabular}{ccccc}
\hline Waktu (menit) & Volume Destilat & Suhu Destilat $\left({ }^{\circ} \mathrm{C}\right)$ & $\begin{array}{c}\text { Volume Minyak } \\
(\mathrm{ml})\end{array}$ & $\begin{array}{c}\text { Rate Destilat } \\
\text { (vol/waktu) }\end{array}$ \\
\hline 15 & $45 \mathrm{ml}$ & 27 & - & 3 \\
\hline 30 & $110 \mathrm{ml}$ & 27 & 0,25 & 3,7 \\
\hline 45 & $125 \mathrm{ml}$ & 27 & 0,4 & 2,8 \\
\hline 60 & $70 \mathrm{ml}$ & 27 & 0,3 & 1,17 \\
\hline
\end{tabular}

\section{Indeks Bias}

Pengujian indeks bias merupakan salah satu analisa yang dilakukan untuk menentukan kemurnian minyak. Besar kecilnya indeks bias dan bobot jenis berhubungan dengan perbandingan komponen-komponen senyawa yang terkandung di dalamnya. Indeks bias dipengaruhi oleh jumlah ikatan rangkap dan panjang rantai karbon, semakin banyak senyawa yang memiliki ikatan rangkap atau fraksi-fraksi berat maka kerapatan minyak akan bertambah besar. Cahaya sulit dibiaskan pada kerapatan minyak yang besar sehingga nilai indeks bias juga akan semakin besar. Selain itu, indeks bias juga dipengaruhi oleh air yang terdapat dalam minyak, semakin banyak kandungan air 
dalam minyak maka nilai indeks bias semakin kecil. Minyak atsiri yang memiliki kualitas bagus adalah minyak atsiri dengan nilai indeks bias yang besar. Berdasarkan hasil analisa, nilai indeks bias minyak atsiri kulit jeruk manis yang diperoleh adalah 1,4672. Nilai indeks bias tersebut hampir mendekati standar Essential Oil Association EOA, yaitu 1,471-1,475.

\section{Analisa GC-MS}

Minyak yang telah dipisahkan dari air, dianalisa menggunakan GC-MS untuk mengetahui komponen yang terdapat dalam minyak atsiri kulit jeruk. Metode yang dapat digunakan untuk mengidentifikasi senyawa yang terdapat dalam suatu campuran diantaranya GC-MS dan LC-MS. GC-MS adalah suatu teknik untuk memisahkan campuran komponen yang bersifat volatil (mudah menguap), sedangkan LC-MS digunakan untuk memisahkan senyawa yang larut dalam zat cair dan bersifat tidak mudah menguap, sehingga LC-MS tidak cocok untuk minyak atsiri karena minyak atsiri bersifat mudah menguap. Selain itu, LC-MS membutuhkan proses preparasi yang lama dan tingkat kemurnian sampel yang tinggi, instrumentasinya mahal serta operator terlatih (Maryam, 2007). Pada penelitian ini digunakan analisa GC-MS karena dapat mengidentifikasi komponen apa saja yang terkandung dalam minyak atsiri kulit jeruk manis. Senyawa-senyawa yang terpisah dari analisis GC akan keluar dari kolom dan mengalir kedalam MS, kemudian senyawasenyawa tersebut teridentifikasi berdasarkan bobot melekul.

Menurut penelitian Megawati, dkk., 2015, komponen utama yang terdapat dalam minyak atsiri kulit jeruk manis adalah limonen yaitu sebesar 96,69\%. Semakin banyak kandungan limonen yang terdapat dalam minyak atsiri kulit jeruk manis maka semakin baik mutu minyak atsiri tersebut.

Berikut merupakan hasil analisa GCMS minyak atsiri kulit jeruk manis dengan dengan proses ekstraksi menggunakan microwave bydrodiffusion and gravity (MHG)

D: GC-MS 2017 \Universitas tribhuwana tunggadewi joice G 10.qgd

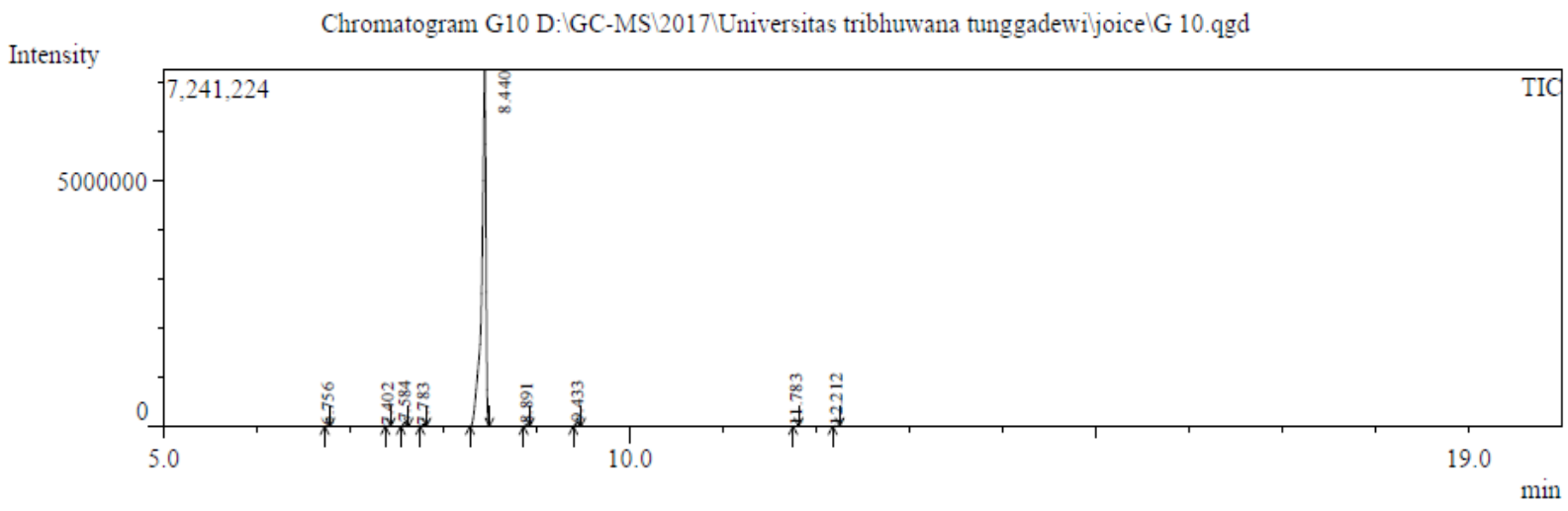




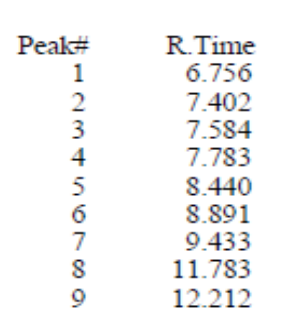

$\begin{array}{rr}\text { Area } & \text { Area\% } \\ 17346 & 0.07 \\ 20630 & 0.09 \\ 169027 & 0.73 \\ 47601 & 0.21 \\ 22623980 & 97.78 \\ 52123 & 0.23 \\ 162270 & 0.70 \\ 11517 & 0.05 \\ 33024 & 0.14 \\ 23137518 & 100.00\end{array}$

\begin{tabular}{rrr} 
& \multicolumn{2}{c}{ Peak Report TIC } \\
Height & Height $\%$ & A/H \\
9252 & 0.12 & 1.87 \\
10584 & 0.14 & 1.94 \\
79585 & 1.06 & 2.12 \\
23126 & 0.31 & 2.05 \\
7241224 & 96.70 & 3.12 \\
25928 & 0.35 & 2.01 \\
76782 & 1.03 & 2.11 \\
6032 & 0.08 & 1.90 \\
16026 & 0.21 & 2.06 \\
7488539 & 100.00 &
\end{tabular}

\section{Gambar 1. Hasil Analisa GC-MS Minyak Atsiri Kulit Jeruk Manis}

Berdasarkan hasil analisa kromatografi gas (GC) diperoleh 9 puncak dengan retention time yang berbeda-beda sesuai dengan jenis senyawa yang dianalisa. Adapun puncak tertinggi muncul dengan retention time 8.440 dengan luas area $22623980(97,78 \%)$ dan height 7241224 (96,70\%). Height (tinggi puncak) adalah jarak dari garis alas sampai maksimal puncak biasanya dalam $\mathrm{mm}$, sedangkan luas area adalah luas daerah dibawah puncak, dan menunjukkan kelimpahan suatu komponen. Retention time adalah selang waktu yang diperlukan oleh zat terlarut (komponen) untuk keluar dari kolom dan mencapai detektor. Kolom GCMS yang digunakan yaitu merek QP2010 PLUS, dengan fase diam berupa senyawa polar dan fase gerak berupa senyawa non polar, yaitu menggunakan gas helium $(\mathrm{He})$ sebagai gas pembawa. Semakin lama zat terlarut berinteraksi dengan fase diam yang bersifat polar maka semakin lama zat terlarut keluar, sehingga retention timenya semakin besar. Dari penjelasan tentang retention time, dapat diketahui kepolaran senyawa pada masing-masing puncak. Senyawa yang keluar pertama yaitu senyawa metil ester dengan retention time 6.756 memiliki sifat yang sama dengan fase geraknya yaitu bersifat nonpolar, sedangkan senyawa yang terakhir keluar (1-butene,3,3-dimetil) dengan retention time
12.212 memiliki sifat yang sama dengan fase diam yaitu bersifat polar. Puncak dengan waktu retensi berbeda menunjukkan jumlah komponen yang terkandung dalam minyak atsiri kulit jeruk manis. Hasil pemisahan kromatografi gas (GC) dianalisa dengan mass spectrometry (MS) untuk mengetahui berat molekul.

\section{KESIMPULAN}

1. Metode Microwave Hydrodiffusion and Gravity (MHG) mampu menghasilkan rendemen minyak atsiri sebesar 0,95 $\mathrm{ml} / 400 \mathrm{~g}$ kulit jeruk manis.

2. Indeks bias minyak atsiri kulit jeruk manis yang diperoleh dari metode Microwave Hydrodiffusion and Gravity sebesar 1,4672 pada suhu $20{ }^{\circ} \mathrm{C}$.

3. Penggunaan pemanas microwave untuk ekstraksi minyak dapat mempersingkat waktu destilasi dan meningkatkan jumlah rendemen minyak.

4. Berdasarkan hasil analisa kromatografi gas (GC) diperoleh 9 puncak dengan retention time yang berbeda-beda sesuai dengan jenis senyawa yang dianalisa. Adapun puncak tertinggi muncul dengan retention time 8.440 dengan luas area $22623980(97,78 \%)$ dan height 7241224 (96,70 \%). Height adalah jarak dari garis alas sampai maksimal puncak biasanya dalam $\mathrm{mm}$, 
sedangkan luas area adalah luas daerah dibawah puncak, dan menunjukkan kelimpahan suatu komponen. Retention time adalah selang waktu yang diperlukan oleh zat terlarut (komponen) untuk keluar dari kolom dan mencapai detektor.

\section{DAFTAR PUSTAKA}

Anshori, Jamaluddin Al dan Ace Tatang Hidayat. 2006. "Konsep Dasar penyulingan dan Analisa Sederhana Minyak Nilam” Jurnal Penelitian.

Astarini, N., Perry, B.R.Y. dan Yulfi, Z. 2010. Minyak Atsiri Dari Kulit Buah Citrus grandis, Citrus aurantium (L.) dan Citrus Aurantifo- lia (Rutaceae) sebagai Senyawa Anti bakteri dan Insektisida. Surabaya: Jurusan Kimia Jurusan Kimia Fakultas Matematika dan Ilmu Pengetahuan Alam Institut Teknologi Sepuluh November.

Chemat F, Abert Vian M, Fernandez X, Visioni F,. 2008. Microwave bydrodiffusion and gravity: a new technique for extraction of essential oils. Journal of Chromatography A, Vol. 1190:14-17.

Ferhat M. A, Meklati B, Smadja J., Chemat F,. 2006. An Improved Microwave Clevenger Apparatus For Distillation Of Essential Oils From Orange Peel. Journal of Chromatography A, Vol 1112, hal. 121-126.

Fong, O. H. 2012. Extraction Of Essential Oil From Orange Peels. Thesis. Faculty of Chemical \& Natural Resources Engineering, University Malaysia Pahang.
Guenther, Ernest. 1987. Minyake Atsiri Jilid I. Penerjemah Ketaren S. Universitas Indonesia Press. Jakarta.

Guenther, E. 1990. The Essential Oils, Diterjemahkan oleh Ketaren S. Minyak Atsiri. Jilid IV B. Ja- karta: Penerbit Universitas Indonesia Press.

Megawati dan Kurniawan, R, D. 2015. Ekstraksi Minyak Atsiri Kulit Jeruk. Manis (Citrus Sinensis) dengan Metode Vacuum Microwave Asssted Hydrodistillation. JBAT 4 (2): 61-67

Sastrohamidjojo dan Pranowo, 1985. Spektroskopi Liberty, Yogyakarta

Sudaryanti, T dan Sugiharti, E. 1990. Budidaya dan Penyulingan Nilam. Penebar Swadaya. Jakarta

Tarwiyah, K. 2001. Minyak Kulit Jeruk. Teknologi Tepat Guna Agroindustri Kecil Sumatera Barat. Hasbullah. Dewan Ilmu Pengetahuan. Teknologi dan Industri Sumatera Barat 